\title{
Low-cost technology for COVID-19 infection detection through smell loss test: An overview
}

\author{
Swain, K.C.* and Singha, C. \\ Department of Agricultural Engineering, Institute of Agriculture, Visva-Bharati (A Central University), \\ Sriniketan, West Bengal 731236, India \\ *Corresponding author e-mail: swainkc@yahoo.com \\ Received 15 April 2020; received in revised form 6 June 2020; accepted 9 June 2020
}

\begin{abstract}
Corona virus (COVID-19) infection has been growing as a biggest threat to human society. World Health Organization (WHO) has already declared it as a pandemic for the whole world, with nearly six million positive cases. Highly contagious nature of the virus has challenged the medical facilities of all the developed and developing country health system. Early identification of the infection is very important to provide medical facilities and cease the chain of infection to new persons. The symptoms such as fever, dry cough, breathing issues generally show in patients not before 5-7 days. However, the patients feel the loss of smell or taste (anosmia) as early as second day onwards due to the presence of virus in nose and throat. Low-cost techniques such as SniffIn-sticks ${ }^{\circledR}$ Smell Test and UPSIT etc. can be used to test anosmia along with medically approved olfactory test leading to identification of COVID-19 infections. With leading researchers findings anosmia test will be effective in breaking the chain infection of COVID-19 virus. In the exit ports, anosmia test kits may be added to thermal testing to identify the infected patients with low symptoms. Additionally, home test kits may be developed at low cost and supplied for large scale testing of the infection.
\end{abstract}

\section{INTRODUCTION}

Corona virus (COVID-19) is a large group of viruses that consist of a core of genetic material surrounded by an envelope with protein spikes which gives the appearance of a crown and in Latin is called "Corona" and that's how these viruses get their name. There are different types of corona viruses that cause respiratory and sometimes gastrointestinal symptoms. Respiratory disease can range from the common cold to pneumonia and in most of the people the symptoms tend to be mild. However, there are some types of corona viruses that can causes severe disease; these include the severe acute respiratory syndrome by corona virus first identifies in China in 2003 and the Middle east respiratory syndrome corona virus that was first identified in Saudi Arabia in 2012 (de Wit et al., 2016).
Chen et al. (2020), reported that the 2019 novel corona virus was first identified in China; it initially occurred in a group of people with pneumonia who had been associated with a seafood and live animal market in city of Wuhan. The disease has since spreads from those who sick to others including family members and health care staff. There are nearly millions of cases present and has been spread to almost all countries in the world.

It is known that corona viruses circulate in a range of animals; sometimes these viruses can make the jump from animals to humans this is called spillover and could be due to a range of factors such as mutations in the virus or increase contact between human and animals for example murska $\mathrm{V}$ is known to be transmitted from camels and Tsarskoe $\mathrm{V}$ from civet cats. The animal reservoir of the 2019 novel corona virus is 
not known yet (WHO, 2020). The disease was first identified in December 2019 in Wuhan, the capital of China's Hubei province, and has since spread globally, resulting in the ongoing 2019-20 coronavirus pandemic (Hui et al., 2020). In a timeline that reaches the present day, an epidemic of cases with unexplained low respiratory infections detected in Wuhan, the largest metropolitan area of China's Hubei province, was first reported to the WHO Country Office in China, on December 31, 2019. However, there is instance of spilling of virus from human to animals, COVID-19 infection in pet animals such as dogs in China and recently to wild animals where Bronx zoo tiger 'Nadia' tests positive for Covid-19, develops dry cough, loss of appetite in New York Zoo.

Corona virus disease 2019 (COVID-19) infection is a contagious disease causing severe acute respiratory syndrome as identified by WHO (2020). SARS-CoV-2 corona virus or COVID-19 put into the human host cells and to develop a strategy to block it. Research findings showed that SARS-CoV-2 requires a cellular protein or protease present in the human body called TMPRSS2 to enter hosts' cells. This protease is a potential target for therapeutic intervention.

In a meeting on January 30, 2020, per the International Health Regulations (IHR, 2005), the outbreak was declared by the WHO a Public Health Emergency of International Concern (PHEIC) as it had spread to 18 countries with four countries reporting human-to-human transmission Mahtani (2020). On February 11, 2020, the WHO Director-General, Dr. Tedros Adhanom Ghebreyesus, announced that the disease caused by this new CoV was a "COVID-19," which is the acronym of "coronavirus disease 2019 " which is a novel (new strain of) virus belonging to the coronavirus (CoV) family. On March 11, as the number of COVID-19 cases outside China has increased 13 times and the number of countries involved has tripled with more than $6,41,6828$ cases in 188 countries and over 3,82,867 deaths (Table 1), WHO declared the COVID-19 a pandemic (Gallegos, 2020; Ramzy and McNeil, 2020). This virus the transmission is believed to occur through respiratory droplets from coughing and sneezing. Aerosol transmission is also possible in case of protracted exposure to elevated aerosol concentrations in closed spaces. As is common with infections, there is a delay between the moment when a person is infected with the virus and the time when they develop symptoms. This is called the incubation period. A pooled analysis of 181 confirmed cases of COVID-19 the incubation period for COVID-19 is typically five to six days but may range from 2 to 14 days. $97.5 \%$ of people who develop symptoms will do so within 11.5 days of infection Lauer et al. (2020). Presentations of COVID-19 have ranged from asymptomatic/mild symptoms to severe illness and mortality. Symptoms may develop 2 days to 2 weeks following exposure to the virus (CDC 2019). Fuk-Woo et al. (2020), reported a case of five patients in a family cluster, which confirmed Personto-person transmission of CoVID-19. Health officials have identified evidence of transmission along a chain of 4 "generations" (a person who originally contracted the virus from a nonhuman source infected someone else, who infected another individual, who then infected another

Table 1. World COVID-19 infection for different region (WHO, 2020)

\begin{tabular}{clcc}
\hline Sl. No. & Region & Infection Cases & Death \\
\hline 1 & Africa & 115639 & 2858 \\
2 & America & 3022824 & 168553 \\
3 & Eastern Mediterranean & 570026 & 13458 \\
4 & Europe & 2211148 & 182308 \\
5 & South-East Asia & 309597 & 8610 \\
6 & Western Pacific & 186853 & 7067 \\
\hline Total & World & 6416828 & 382867 \\
\hline
\end{tabular}


individual), suggesting sustained human-tohuman transmission (Phelan et al., 2020).

The world COVID-19 positive cases have been increased to 6.5 Million in five months (Worldometers, 2020). The number of confirmed cases of COVID-19 is lower than the number of total cases (Fig. 1). The main reason of this is limited testing, which need to be increased for early detection of the COVID-19 infection. Still testing has been bottle neck in checking the spreading of COVID-19 infection (Fig. 2). India is lagging far behind in total testing $(<0.5 \%$ of total population.

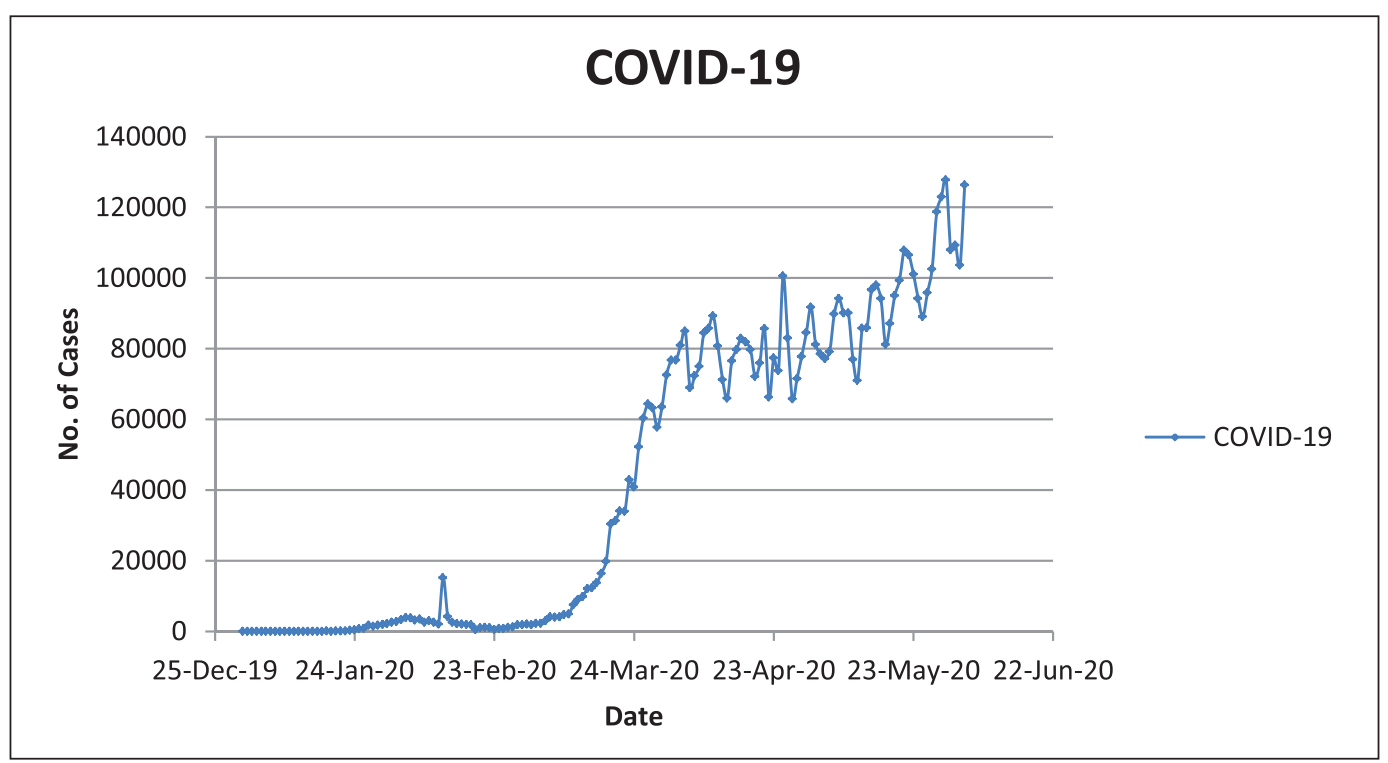

Figure 1. World trend of COVID-19 Infection (https://ourworldindata.org/)

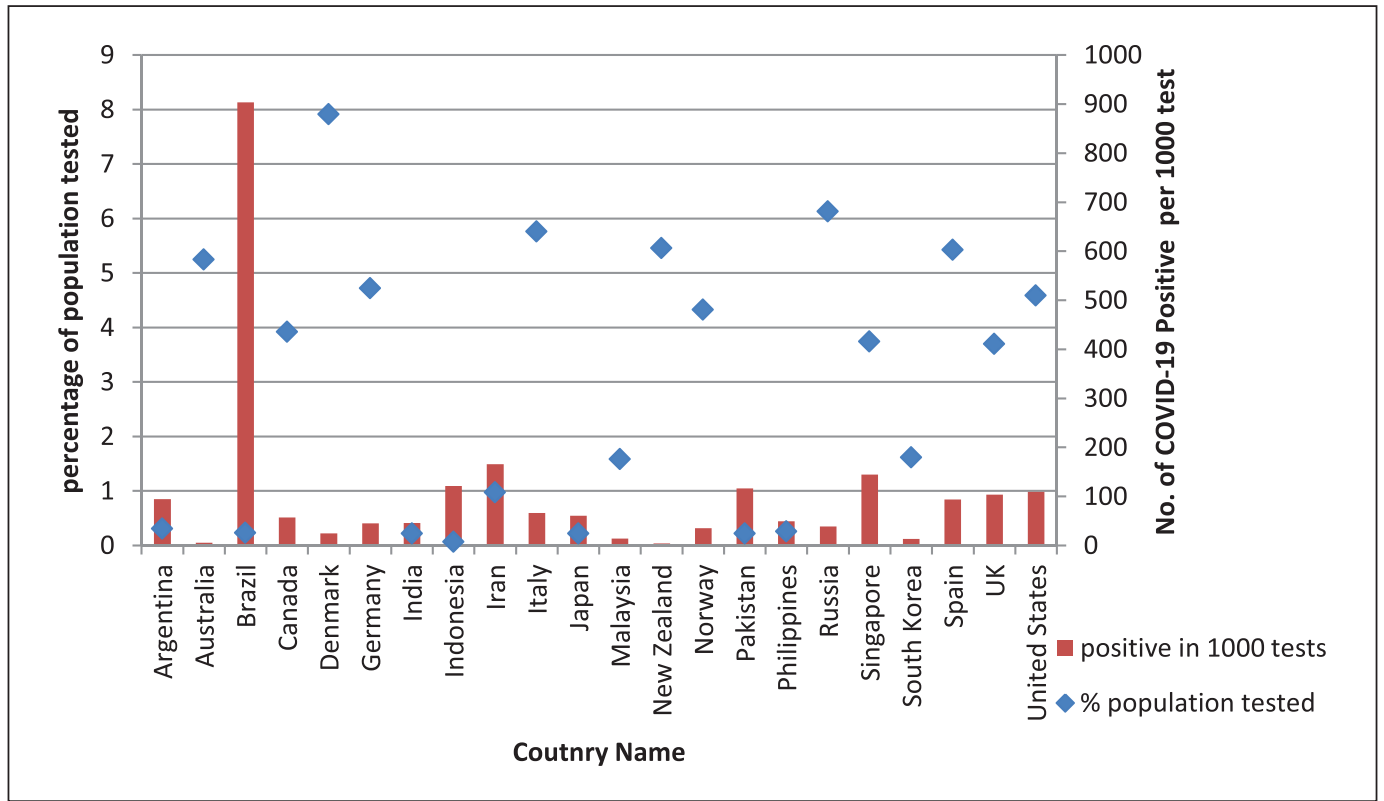

Figure 2. Testing statistics of COVID-19 (WHO, 2020) 
This shows the importance of alternative testing technique for COVID-19. According to Khan et al. (2020), the COVID-19 epidemic became a serious challenge for the healthcare authorities, scientific community, and the infections controlling agencies across China, in terms of spread, treatment, and prevention. Pneumonia appears to be the most frequent manifestation of infection, characterized primarily by fever, cough, dyspnea and bilateral infiltrates on chest imaging (Huang et al., 2020). The overall case fatality rate is uncertain but appears to be around 3 percent and slowly sliding upward.

\section{Symptomatic result}

Symptoms of COVID-19 can be relatively non-specific and infected people may be asymptomatic. Human infection with COVID-19 leads to a wide range of clinical manifestations ranging from asymptomatic, mild, and moderate to severe (Fung et al., 2020). The COVID-19 outbreak was designated a pandemic on March 11th, and has rapidly spread worldwide. Nations have implemented disease control measures including travel restrictions, expanded triage and quarantine, and screening measures like temperature checkpoints (Xiaoting et al., 2020). More than half of patients are a febrile early in the disease course, and mild or asymptomatic patients can spread SARSCoV-2 with high efficiency (Guan et al., 2020). Besides cough, patients can present with heterogeneous symptoms including sore throat, headache, nasal congestion, anosmia, tonsil swelling, and conjunctivitis. These symptoms overlap with common diseases including influenza and URIs, making clinical diagnosis difficult. SARS-CoV-2 is present in high concentrations in the nose and throat in symptomatic and asymptomatic patients (Zou et al., 2020).

Pneumonia of unknown cause detected in Wuhan, China was first reported to the WHO Country Office in China on 31 December 2019. As they were unable to identify the causative agent, these first cases were classified as "pneumonia of unknown etiology".
Common symptoms include fever, cough, and shortness of breath. Other symptoms may include muscle pain, diarrhea, sore throat, loss of smell, and abdominal pain while the majority of cases result in mild symptoms, some progress to viral pneumonia and multiorgan failure (Hopkins, 2020). In one of the first reports on the disease, Huang et al. (2020), illustrated that patients (around 41) suffered from fever, malaise, dry cough, and dyspnea. Chest computerized tomography (CT) scans showed pneumonia with abnormal findings in all cases. In general, estimates suggest that $2 \%$ of the population is healthy carriers of a $\mathrm{CoV}$ and that these viruses are responsible for about $5 \%$ to $10 \%$ of acute respiratory infections (Chen $e t$ al., 2020). Clinical and preclinical research will have to explain the pathogenesis of the cytokine release syndrome (CRS) that is an acute systemic inflammatory syndrome characterized by fever and multiple organ dysfunction. Cascella et al. (2020) details explain features, evaluation and treatment Coronavirus (COVID-19) for fatal cases, encapsulates, asymptomatic cases, respiratory failure, sepsis, septic shock, and/or multiple organ dysfunction, severe pneumonia etc.

\section{ANOSMIA WITH COVID-19}

Anecdotal reports from clinicians and patients during the 2019-2020 pandemic suggest that infection with COVID-19 is associated with high rates of disturbances in smell and taste perception (anosmia/ hyposmia, ageusia and/or dysgeusia), (Gale, 2020; Bienkov, 2020). On March 20, 2020 the Ear, Nose, and Throat Society of the UK and the British Rhinological Society issued a bulletin detailing a strong anecdotal association between Covid-19 infection and anosmia/hyposmia in physician reports from South Korea, China, Italy, France and the United States; this bulletin further argued that individuals with new onset anosmia should self-isolate based upon presumed COVID-19 infection (Hopkins, 2020). Even the American Academy of Otolaryngology 
proposed that anosmia, hyposmia and dysgeusia (in the absence of other respiratory disease) should be added tosymptoms used for screening for COVID-19 infection, and urged precautionary isolation for individuals with these symptoms (Anosmia, 2020).

An analysis by a team at King's College London showed that $59 \%$ of COVID-19 positive patients reported a loss of smell and taste, compared with only $18 \%$ of those who tested negative for the disease. These results were much stronger in predicting a positive COVID-19 diagnosis than self-reported fever, he added (Koshay, 2020).

Recently Shannon (2020), reported that lost sense of smell may be peculiar clue to Coronavirus Infection. It differs from hyposmia which is a decreased sensitivity to some or all smells. However, olfactory and taste disorders are well known to be related with a wide range of viral infections (van Riel et al., 2015). SARS-CoV has also demonstrated in mice model a transneural penetration through the olfactory bulb (Netland et al., 2008). Moreover, angiotensin converting enzyme 2 receptor, which is used by SARS-CoV-2 to bind and penetrate into the cell, is widely expressed on the epithelial cells of the mucosal of oral cavity (Xu et al., 2020). These evidences could explain the underlying pathogenetic mechanism of taste and olfactory disorders in SARS-CoV-2 infection. Characteristic of patients with COVID-19 infection assessed for taste and olfactory disorders. According to Giacomelli et al. (2020), females reported OTDs more frequently than males [10/19 (52.6\%) versus $10 / 40$ (25\%), $\mathrm{P}=0.036$ ].

Hopkins (2020), also found evidence for the loss of smell as a symptom of COVID-19 infection. There is already good evidence from South Korea, China and Italy that significant numbers of patients with proven COVID-19 infection have developed anosmia/hyposmia may be some of the hitherto hidden carriers that have facilitated the rapid spread of COVID-19. In Germany it is reported that more than 2 in 3 confirmed cases have anosmia. In South Korea, widespread testing has found that almost $30 \%$ of confirmed patients have anosmia as the major presenting symptom. In addition, there have been a ever increasing numbers of patients presenting with anosmia in the absence of any other symptoms. Iran has reported a sudden increase in cases of isolated anosmia, and many colleagues from the US, France and Northern Italy have the same experience. British Rhinological Society and a group called Ear, Nose, and Throat U.K. arguing that a loss of sense of smell is a marker of COVID-19 infection. British letter wrote that in South Korea, where early testing was widespread, nearly 30 percent of patients testing positive for virus have had anosmia as their primary presenting symptoms in otherwise mild cases. It is still possible that anosmia becomes an important signal and a more prevalent symptom for COVID-19 than for other kinds of respiratory infections; it's also possible that it ends up being more similar to coughing - a common symptom of COVID-19 but not a clear sign of infection on its own. Gareth (2020) explained experts also need to sniff out whether the symptoms are an indication of covid-19 or of allergies, colds, or seasonal flu, which can all cause anosmia or ageusia. Hopkins and Kumar (2020) went on step further for warning the adults. If adults feels the loss of smell but no other symptoms should self-isolate for seven days alongside people with more established symptoms. We might be able to identify and reduce the number of otherwise asymptomatic people continue to act as vectors for infection.

The American Academy of Otolaryngology described that lost smell, as well as distorted smell and taste, are being commonly seen in otherwise healthy COVID19 patients. There is rapidly accumulating anecdotal evidence that anosmia with resultant dysgeusia are frequently reported symptoms associated with the COVID-19 pandemic. Similar reports are surfacing from multiple countries around the world including the United States. The American Academy of Otolaryngology-Head and Neck Surgery (AAO-HNS), in an effort to find the significance of these symptoms in diagnosis and progression of COVID-19 infection, has found the COVID-19 Anosmia Reporting Tool 
for Clinicians. Peter Brennan, Reader in Physiology from the University of Bristol says that COVID-19 could be killing off these olfactory sensory neurons, keeping the signal of what you've just smelled from getting to your brain. A complete or partial loss of the sense of smell (anosmia) has also been reported during history finding in patients eventually diagnosed with COVID-19 (Rabin, 2020). Weisberger (2020) reported that up to $70 \%$ of patients who test positive for the coronavirus disease COVID-19 have anosmia. It is still unknown that the coronavirus wreaks havoc on our sense of smell by killing olfactory sensory neurons, by disrupting their function or by otherwise impacting nasal olfactory tissues. More research is required to understand this link, but it has potential to provide a low-cost, practical indicator so that people should get self-isolated or got further testing.

Nerve cells responsible for smell may be damaged by the virus and so went looking through datasets to see if the cells contained ACE2 and one other protein that helps SARS-CoV-2 get inside cells. Brann et al. (2020), suggested a possible mechanism through which CoV-2 virus infection could lead to anosmia or damage olfactory organism in COVID-19 patients. Two nasopharyngeal swabs and one sputum sample were obtained and were found to be positive for COVID-19 on quantitative reversetranscriptase - polymerase-chain-reaction Two nasopharyngeal swabs and one sputum sample were obtained and were found to be positive for COVID-19 on quantitative reversetranscriptase polymerase-chain reaction Transmission of COVID-19 Infection from an Asymptomatic contacts also in Germany (Rothe et al., 2020).

This study can help India filter Covid-19 patients and silent carriers of novel coronavirus better at a time when almost all states have enforced partial or total lockdown imposing curfew as experts say India has reached the stage where community transmission might take off (Dutta, 2020).

\section{SCOPE OF ANOSMIA DETECTION OF COVID-19}

Most of the COVID-19 patient shows symptoms like fever, dry cough and breathing issues along with loss of smell and taste. Sometimes, even COVID-19 infected person sometimes do not have symptoms of fever, cough or other typical symptoms, experienced loss of smell, or ageusia, a loss of taste. The British Association of Otorhinolaryngology (ENT UK) identified that the most of the asymptomatic patients ones who do not have a fever or a cough could show a loss of smell or taste as symptoms after contracting coronavirus.

People with COVID-19 generally develop signs and symptoms, including mild respiratory symptoms and fever, on an average of 5-6 days after infection (mean incubation period 5-6 days, range 1-14 days). Nearly $5 \%$ people showed only nasal congestion when infected with COVID-19 virus. As we understand, the dissemination of virus in the human body takes a slow pace. The symptoms of it presence shows nearly 5 days after entering the body and sometimes display of symptoms delayed as late as 28 days.

Numerous reports of loss of sense of smell and taste have been received from Iranian people as one of the most heavily involved countries with COVID-19 during the outbreak of the disease (Farda, 2020; IFP, 2020). Michelen et al. (2020) found that amongst individuals with sufficient symptoms at RT-PCR test, prevalence of anosmia was many fold higher (nearly 60\%) in those testing positive compared to those testing negative (nearly 20.0\%) for COVID RADAR survey. Loss of smell may therefore be a good predictor of COVID-19 infection (Thevarajan et al., 2020). Russell et al. (2020) summarised the evidence on the existence of anosmia and ageusia an emerging COVID-19 symptoms in order to better inform both oncology patients and clinicians. 
The primary causes of anosmia include obstruction (blockage) of the nasal passageways, destruction of the tissue lining the nose through inflammation or swelling, and a loss of nerve transmission from sensory neurons in the nose to the brain. However, COVID-19 found to infect the supporting cells of olfactory glands in nose. Additionally, the losses of taste and smell continue until the virus stay at the throat region of the infected person. It happens well before displaying severe symptoms of the infection.

\section{TECHNIQUES FOR ANOSMIA DETECTION}

It is very important to detect the virus through low cost technique and at earlier stage of the infection. The standard olfactory techniques can be directly used for identifying the infection of COVID-19 at earlier stage. However, testing at medilabs will take lot of time and energy. The resources may not be sufficient enough to meet the demand of the infected patients and an asymptotic person.

\section{UPSIT Technique}

The Smell Identification Test ${ }^{\mathrm{TM}}$ [UPSIT] is a comprehensive 40-item test. It is the most reliable (test-retest $\mathrm{r}=0.94$ ) and accurate olfactory test available following the worldwide standard for olfactory testing. It is the most widely used olfactory test, having been administered to nearly 1,000,000 people worldwide. It is easily self-administered in 10-15 minutes. Developed at the University of Pennsylvania with funding from the National Institutes of Health, the UPSIT is comprised of 4 booklets, each containing 10 microencapsulated (scratch \& sniff) odors.

\section{SniffIn-sticks ® Smell Test (SS)}

The 12 odorants in the SniffIn-sticks ${ }^{\circledR}$ test are Orange, Leather, Cinnamon, Peppermint, Banana, Lemon, Liquorice, Coffee, Cloves, Pineapple, Rose, and Fish. The sticks were placed $1 \mathrm{~cm}$ from one nostril and the patient was asked to inhale with the other nostril closed and the test repeated in the other nostril. The subjects were asked to identify the correct smell, from a set of four choices for each item, from an answer card. First response was taken and scored 1 for correct and 0 for wrong answer (George et al., 2013).

\section{INSIT technique}

The essence of 10 commonly used items were used as odorants. The essence of cardamom, kewra, khus, lemon, mango, orange, pineapple, rose, thinner, and vanilla in 20-mL airtight bottles commercially available were used. Cotton buds dipped in the essence were used as test material, which was placed $1 \mathrm{~cm}$ in front of the one nostril with the other nostril closed and repeated in the other side. The subjects were asked to sniff and identify the smell from the answer card containing four choices for each odorant. The first response was taken and scored 1 for correct response and 0 for wrong response (Nehara et al., 2019).

\section{Testing Ansomia at the check points}

There is strict requirement of testing the COVID-19 patients before entering into the crowded places such as airport, railway stations, bus stand or shopping malls etc. The COVID-19 asymptotic patients need to be traced out earlier to check the chain transmission. There is also requirement to identify the patients who are hiding the symptoms by using medicines to reduce body temperature or cough. Early detection will also increases and ensure quick recovery.

Test kit consisting of 5 locally available materials with distinct smell can be packed in small use and through plastic tubes. The materials should be in dust or grounded form of uniform textural size to hinder their identification visually. No label may be given on the bottle of identical sizes to make them ready for Olfaction identification test. However, for quick testing, the identification marks may be given below or side of the bottle. Separate marked sheet may be used to put the bottles on it.

The low-cost locally available material may be used to identify the infected person. This type of system can be produced locally and at faster pace. Additionally, the sticks used take the swab can also be dipped in the bottles containing liquid form of the materials and asked to identify by persons. 


\section{LABORATORY TESTING OF COVID-19}

Down the line, for confirmatory testing of COVID-19 still Reverse-Transcription Polymerase Chain Reaction (RT-PCR) test has been entrusted with, as it directly tests the presence of virus RNA (Green $e t a l$., 2020). RT-PCR tests are fairly quick, sensitive and very reliable, capable of producing results within 3-4 hours, although this usually takes longer for transportation of samples to the facility and its return along with other logistics.

Additionally, a pulse oximeter has been used to check the blood oxygen level as a symptom of COVID-19 infection if there is no other known issue with the person (Daily, 2020; Rauf, 2020). The pulse oximeter transmits light from sensors on one side of the device through the body part to sensors on the other side. It calculates how much oxygen is being transported through the person's bloodstream and displays the results as a percentage within fifteen seconds (Daily, 2020). Low level of oxygen shows presence of illness in the person and warns it of possible danger.

\section{DISCUSSION}

This technique can give early warning of the presence of the virus in the body particularly nose or throat area. Most of the time the virus may not started infecting the other people. As of new cases, there is absence of the symptoms like fever, cough etc. but infection is at higher level requiring intensive care. Loss of smell and taste may even be checked at home without any equipment. But, COVID19 may not be only cause of loss of smell or taste. However, unusual loss of smell or taste after coming across some of the infected person or surrounding may be used as symptom for further checking and self quarantine.

The huge loss of life due to COVID-19 infection in whole world is alarming to the world leaders and economists. The identification has been challenging due to the pattern of infection of COVID-19 virus. It remains in winter sleep mode for at least one week, without showing any visible symptoms. So, the hosted person has no information of its infection. However, unknowingly the infected person continued his normal life and infected the persons surrounding him. As a general estimation one virus infected person can directly infect at least 406 persons just in a month and as per the chain reaction each infected individual will infect next 406 persons since its gets the virus inside its body. The spreading of the COVID-19 virus is going to cause huge economic losses too. But, to save life, early identification and treatment is very much necessary all over the infected areas and at the transportation port.

As we currently come across the share of asymptotic cases of COVID-19 infection has been in rise in different part of the world (Cox, 2020), which needs more specific and time bound research work. Additionally, the loss of taste and smell may also be caused due to sinucites, allergies, nasal polyps, smoking, and specific medication including aging over 60 years etc. (Takahashi, 2019), may raises doubt on test results.

\section{LIMITATIONS OF THE STUDY}

In addition to COVID-19, loss of smell can also result from allergies as well as other viruses, including rhinoviruses that cause the common cold. So, anosmia alone does not mean you have COVID-19. Studies are being done to get more definitive answers about how common anosmia in people with COVID19 , at what point after infection loss of smell occurs, and how to distinguish loss of smell caused by COVID-19 from loss of smell caused by allergies, other viruses, or other causes altogether. The research on anosmia, as a symptom of COVID-19, is still in the primitive stage. More research work in this line should be carried out for early detection of the infection.

\section{CONCLUSION}

Olfactory test has potential to identify COVID19 infections sometimes well before display of primary symptoms like fever, dry cough 
etc. This will also give enough time for taking medical treatment in advance and also break the chain of infection, saving many potential people coming in contact of the patient. The low-cost system will further make the test affordable for common people to protect themselves from COVID-19 infection. Additionally, at the transportation ports, olfactory test could be included with thermal scanning to reduce the percentage of unidentified infected person for early checking of the spreading of the virus.

\section{Conflict of interest}

Authors declare no conflicts of interest.

\section{REFERENCES}

Anosmia (2020). Anosmia, Hyposmia, \& Dysgeusia Symptoms of Coronavirus Disease. Published on 22 March 2020. https://www. entnet.org/content/corona virus-diseas e-2019-resources, Accessed: April 04, 2020.

Brann, H.D., Tsukahara, T., Weinreb, C., Logan, D.W. \& Datta S.R. (2020). Nonneural expression of SARS-CoV-2 entry genes in the olfactory epithelium suggests mechanisms underlying anosmia in COVID-19 patients, bioRxiv 2020.03.25.009084; doi: https://doi.org/ 10.1101/2020.03.25.009084, Accessed: April 03, 2020.

Bienkov, A. (2020). If you've lost your sense of smell or taste, you could be a 'hidden carrier' of the coronavirus, Accessed: March 11, 2020.

Cascella, M., Rajnik, M., Cuomo, A. (2020). Features, Evaluation and Treatment Coronavirus (COVID-19). Treasure Island (FL): StatPearls Publishing; 2020 Jan-.https://www.ncbi.nlm.nih.gov/ books/NBK554776/, Accessed: April 01, 2020.

CDC. (2019). Novel Coronavirus, Wuhan, China: Symptoms. CDC. Available at https://www.cdc.gov/coronavirus/2019ncov/about/symptoms.html. January 26, 2020; Accessed: April 03, 2020.
Chen, X., Liu, J., Li, N., Nisenbaum, E. (2020). Otolaryngology Providers Must Be Alert for Mild and Asymptomatic COVID-19 Patients Otolaryngology-Head and Neck Surgery, https://www.entnet.org/content/ coronavirus-disease-2019-resources, Accessed: April 03, 2020.

Chen, Y., Liu, Q. \& Guo, D. (2020). Emerging coronaviruses: Genome structure, replication, and pathogenesis. Journal of Medical Virology 92(4): 418-423.

de Wit, E., van Doremalen, N., Falzarano, D. \& Munster, V.J. (2016). SARS and MERS: recent insights into emerging coronaviruses. Nat. Rev. Microbiology 14: 523534.

Cox, D. (2020). Could nearly half of those with Covid-19 have no idea they are infected? The Guardian, published on 30 May 2020. https://www.theguardian. com/. Accessed: June 01, 2020.

Daily, L. (2020). What is a pulse oximeter, and does the coronavirus pandemic mean you need one? Published on 19 May 2020, https://www.washingtonpost. com/. Accessed: May 25, 2020.

Dutta , P.K. (2020). Coronavirus thrives on silent carriers. Beware of loss of smell, New Delhi, https://www.indiatoday.in/ coronavirus-outbreak/story/coronavirusthrives-on-silent-carriers-beware-ofloss-of-smell-1659004-2020-03-24, Accessed: April 04, 2020.

Farda, R. (2020). Loss of sense of smell among Iranians coinciding with Coronavirus epidemic. Available via DIALOG. https:// en.radiofarda.com/a/ loss-of-sense-ofsmell-among-iranians-coinciding-withcoronavirusepidemic/30478044.html. Accessed: April 11, 2020.

Fuk-Woo, C.J., Shuofeng, Y. \& Kin-Hang, K. (2020). A familial cluster of pneumonia associated with the 2019 novel coronavirus indicating person-to-person transmission: a study of a family cluster. The Lancet 395: 514-523. 
Fung, S.Y., Yuen, K.S., Ye, Z.W., Chan, C.P. \& Jin, D.Y. (2020). A tug-of-war between severe acute respiratory syndrome coronavirus 2 and host antiviral defence: lessons from other pathogenic viruses. Emerging Microbes \& Infections 9(1): 558-570. https://doi.org/10.1080/22221751. 2020.1736644.

Gale, J. (2020). NBA Player's Loss of Smell Highlights Unusual Marker of Covid-19.

Gallegos, A. (2020). WHO Declares Public Health Emergency for Novel Coronavirus. Medscape Medical News. Available at https://www.medscape.com/ viewarticle/924596. January 30, 2020; Accessed: February 28, 2020.

George, J., Jose, T. \& Behari, M. (2013). Use of Indian smell identification test for evaluating olfaction in idiopathic Parkinson's disease patients in India. Neurology of India 61(4): 365-370.

Guan, W.J., Ni, Z.Y. \& Hu Y. (2020). Clinical Characteristics of Coronavirus Disease 2019 in China. New England Journal of Medicine 382(18): 1708-1720.

Hopkins, C. (2020). Loss of sense of smell as marker of COVID-19 infection. Ear, Nose and Throat surgery body of United Kingdom. Accessed: April 02, 2020.

Huang, C., Wang, Y., Li, X., Ren, L., Zhao, J., Hu, Y., Zhang, L., Fan, G., Xu, J., Gu, X., Cheng, Z., Yu, T., Xia, J., Wei, Y., Wu, W., Xie, X., Yin, W., Li, H., Liu, M., Xiao, Y., Gao, H., Guo, L., Xie, J., Wang, G., Jiang, R., Gao, Z., Jin, Q., Wang, J. \& Cao, B. (2020). Clinical features of patients infected with 2019 novel coronavirus in Wuhan, China. The Lancet 395(10223): 497-506.

Hui, D.S.I., Azhar, E., Madani, T.A., Ntoumi, F., Kock, R., Dar, O., Ippolito, G., Mchugh, T.D., Memish, Z.A., Christian, D. \& Zumla, A. \& Petersen, E. (2020). The continuing 2019-nCoV epidemic threat of novel coronaviruses to global health - The latest 2019 novel coronavirus outbreak in Wuhan, China. International Journal of Infectious Diseases 91: 264-66.

Gareth, I. (2020). Sixty seconds on anosmia. British Medical Journal 368: m1202. doi: 10.1136/bmj.m1202. ISSN 1756-1833. PMID 32209546.
Giacomelli, A., Pezzati, L., Conti, F., Bernacchia, D., Siano, M., Oreni, L. \& Galli, M. (2020). Self-reported olfactory and taste disorders in SARS-CoV-2 patients: a cross-sectional study. Clinical Infectious Diseases doi:10.1093/cid/ ciaa330.

Green, K., Winter A. \& Dickinson, R. (2020). What tests could potentially be used for the screening, diagnosis and monitoring of COVID-19 and what are their advantages and disadvantages? The Centre for Evidence-Based Medicine (CEBM) reports, Published on 20 April 2020. Accessed: April 25, 2020.

Hopkins, C. \& Kumar, N. (2020). Loss of sense of smell as marker of COVID-19 infection. www.entuk.org/loss-sense-smellmarker-covid-19-infection.

IFP Editorial staff (2020). Olfactory disorder getting prevalent in Iran amid Coronavirus outbreak. Available via DIALOG. https://ifpnews.com/olfactorydisordergetting-prevalent-in-iran-amidcoronavirus. Accessed: April 10, 2020.

Khan, S., Siddique, R., Ali, A., Bai, Q., Li, Z., Li, H., Shereen, M.A. \& Xue, M. (2020). The spread of novel coronavirus has created an alarming situation worldwide, Journal of Infection and Public Health, https://doi.org/10.1016/j.jiph.2020.03. 005.

Koshy, J. (2020). Coronavirus-researchersfind-cells-that-may-explain-loss-ofsmell-in-covid-19-patients, https://www. thehindu.com/news/national/corona virus-researchers-find-cells-that-mayexplain-loss-of-smell-in-covid-19patients/article31282353.ece. Accessed: April 29, 2020.

Lauer Stephen, A., Grantz Kyra, H., Bi, Q., Jones, F.K., Zheng, Q., Meredith, H.R., Azman, A.S., Reich, N.G. \& Lessler, J. (2020). The Incubation Period of Coronavirus Disease 2019 (COVID-19) From Publicly Reported Confirmed Cases: Estimation and Application. Annals of Internal Medicine 172(9): 204-218. doi: 10.7326/M20-0504. 
Mahtani, S., Berger, M., O'Grady, S. \& Iati, M. (2020). Hundreds of evacuees to be held on bases in California; Hong Kong and Taiwan restrict travel from mainland China. Accessed: April 10, 2020.

Nehara, H.R., Sharma, B., Kumar, A., Saran, S., Mangalhara, N.K. \& Mathur, S.K. (2019). Correlation of olfactory phenotype by Indian smell identification test and quantitative MRI of olfactory apparatus in idiopathic hypogonadotropic hypogonadism. Indian Journal of Endocrionology and Metabolism 23(3): 367-372.

Michelen, M., Jones, N. \& Stavropoulou, C. (2020). In patients of COVID-19, what are the symptoms and clinical features of mild and moderate cases?, https:// www.cebm.net/covid-19/in-patients-ofcovid-19-what-are-the-symptoms-andclinical-features-of-mild-and-moderatecase/, Accessed: April 11, 2020.

Netland, J., Meyerholz, D.K., Moore, S., Cassell, M. \& Perlman, S. (2008). Severe acute respiratory syndrome coronavirus infection causes neuronal death in the absence of encephalitis in mice transgenic for human ACE2. Journal of Virology 82(15): 7264-7275.

Phelan, A.L., Katz, R. \& Gostin, L.O. (2020). The Novel Coronavirus Originating in Wuhan, China: Challenges for Global Health Governance. Journal of the American Medical Association 10. 1001/ jama.2020.1097.

Rabin, R.C. (2020). Lost Sense of Smell May Be Peculiar Clue to Coronavirus Infection. The New York Times. Available at https://www.nytimes.com/2020/03/22/ health/coronavirus-symptoms-smelltaste.html. March 22, 2020; Accessed: March 30, 2020.

Ramzy, A. \& McNeil, D.G. (2020). W.H.O. Declares Global Emergency as Wuhan Coronavirus Spreads. The New York Times. Available at https://nyti.ms/ 2RER70M. January 30, 2020; Accessed: March 30, 2020.
Rauf, D. (2020). Can a Pulse Oximeter Save Your Life if You Have COVID-19? Published on 14 May 2020. https://www. everydayhealth.com/. Accessed: May 29, 2020.

Rothe, C., Schunk, M., Sothmann, P., Bretzel, G., Froeschl, G., Wallrauch, C., Zimmer, T., Thiel, V. \& Janke, C. (2020). Transmission of 2019-nCoV infection from an asymptomatic contact in Germany. New England Journal of Medicine 382: 970971. doi:10.1056/NEJMc2001468

Russell, B., Moss, C., Rigg, A., Hopkins, C., Papa, S. \& Van Hemelrijck, M. (2020). Anosmia and ageusia are emerging as symptoms in patients with COVID-19: What does the current evidence say? Ecancer 14 ed98.

Shannon, P. (2020). The Key Stat in the NYTimes' Piece About Losing Your Sense of Smell Was Wrong. Slate Magazine. Archived from the original on 28 March 2020. Accessed: March 30, 2020.

Smith, D. (2020). Can pulse oximeters detect coronavirus? How they work and more. Published on 8 May 2020, https://www. cnet.com/. Accessed: May 20, 2020.

Takahashi, P.Y. (2019). Is loss of taste and smell normal with aging? Published on 7 August 2019. https://www.mayoclinic. org/. Accessed: May 20, 2020.

Thevarajan, I., Buising, K.L. \& Cowie, B.C. (2020). Clinical presentation and management of COVID-19, The Medical Journal of Australia - Preprint only - 8 April 2020, https://www.mja.com.au/ journal/2020/clinical-presentation-andmanagement-covid-19, Accessed: April 10, 2020.

van Riel, D., Verdijk, R. \& Kuiken, T. (2015). The olfactory nerve: a shortcut for influenza and other viral diseases into the central nervous system. Journal of Pathology 235(2): 277-87.

Xu, H., Zhong, L., Deng, J., Peng, J., Dan, H., Zeng, X. \& Li, T. (2020). High expression of ACE2 receptor of 2019-nCoV on the epithelial cells of oral mucosa. International Journal of Oral Science 12(1): 8 . 
Weisberger, M. (2020). Loss of smell could be a symptom of COVID-19 https://www. livescience.com/covid-19-symptomsloss-smell-taste.html, Accessed: March 30, 2020.

WHO. (2020). World Health Organization reports, 2020, https://www.who.int/. Accessed: June 4, 2020.
Worldometers (2020). COVID-19 Coronavirus Pandemic, published on 31 May 2020. Accessed: 01 June 2020. www.worldo meters.info.

Zou, L., Ruan, F. \& Huang, M. (2020). SARSCoV-2 Viral Load in Upper Respiratory Specimens of 111 Infected Patients. New England Journal of Medicine 382(12): 1177-1179. https://www.entnet. org/content/reporting-tool-patientsanosmia-related-covid-19. 